\title{
Leprosy and Primary Health Care: the Mandwa Project, India
}

\author{
N H ANTIA \\ The Foundation of Medical Research, 84- A R. G. Thadani Marg, \\ Worli, Bombay 400 018, India
}

Received for publication 23 April 1981

No disease can be controlled, however effective the remedy, if there is failure in detection and regularity of treatment is not assured.

Leprosy control programmes were commenced in most endemic countries of the world about a quarter of a century ago based on the availability, for the first time, of a drug against the disease which was not only highly effective but also safe, cheap and orally dispensable. A separate service was started for leprosy as for many other major health problems like malaria, tuberculosis and smallpox. These were the days of euphoria when we believed science had the answers to most human problems. Twenty-five years later we remain sadder but wiser.

Even in diseases like those which are sexually transmitted and where a single injection can ensure cure, we have failed in achieving success in countries where knowledge is widespread and facilities for treatment are freely available to all. This sad tale has repeated itself for all the diseases where hopes of control were high because of availability of cheap and effective drugs, vaccines or insecticides. Smallpox was the only exception. The blame for such failure has been attributed to many causes such as inadequate funds, nonavailability of drugs, suitable personnel, transport; ignorance and apathy of the people and their rulers, and finally the development of resistance to drugs and insecticides and the nonavailability or the exhorbitant cost of alternative treatment.

Yet we know that most of these diseases were eliminated from the developed countries long before drugs or vaccines were available for their control. Education combined with improvement of the social and economic conditions therefore remains the only certain way of controlling communicable diseases. They are therefore more amenable to social and political action rather than purely medical measures. 
Failure to achieve results despite vast inputs of men and money could have been condoned in the early phases as a genuine lack of appreciation of these factors, but the continuation and expansion of services which have proved to be inadequate or ineffective can only be attributed to the vested interest of professionals, bureaucracy, pharmaceutical industry and politicians in propagating the empires built by them on various diseases. Any new approach, however well based on scientific and/or social reality, is firmly resisted on administrative or technical grounds. Unfortunately, those who have a vested interest in maintaining the status quo are also generally the persons in whom society has vested responsibility for bringing about the necessary changes. In such a system it is also unfortunately true that those whose interests are primarily at stake are seldom involved in making decisions for their own welfare and are treated as passive recipients of health or illness care. In the poor and chiefly rural societies of developing countries this implies that decisions are made by a small coterie of the urban elite, who even if well intentioned, have little concept of the actual problems of the majority of the people with whom they have little physical or cultural affinity.

In the case of leprosy, where the problem of stigma far overrides the problem of technology, our whole approach has been of an almost entirely technical nature. While we have a vast number of medical and paramedical personnel there are hardly any social scientists in the field; by which I do not mean social workers. While we spend increasingly more on research of the scientific aspects of leprosy, including the vaccine, we almost totally ignore research into the equally important social aspects of the disease. Even if an effective vaccine was available, which is problematic, why do we think it will not go the way of all the other vaccines and immunizations? For millions still suffer and die of infectious diseases like tuberculosis, tetanus, poliomyelitis and diphtheria. The failure has been in the delivery of the drugs and vaccines and not in their potency.

Why is it then that despite the availability of drugs and vast investment in manpower and other resources leprosy continues to remain a major health hazard? This is not to say that no benefits have accrued; the problem may have been worse without such programmes. But it is also clearly evident that mere detection and distribution of pills cannot succeed. The answer lies in the fact that the techno-bureaucratic approach has failed to understand or has ignored the significance of stigma which plays a predominant role in this disease and without whose appreciation no programme for leprosy control can ever succeed.

Should we then not try to study the real causes of the stigma as it affects the various segments of our population and how they perceive the disease and its sufferers? Should we not find out why the medical profession itself has such an unscientific fear of the disease as it has of no other? Can we expect health education of the public to succeed when the medical profession which is 
looked to for guidance on medical problems refuses to handle leprosy patients and admit them to hospitals? In actual fact the stigma is most marked in the educated and not so great among the less educated masses. Yet being the decision makers, whether in medicine or employment they play a major negative role.

The approach of the patient to this disease also affects early detection, regularity of treatment and his rehabilitation for without his co-operation little can be achieved. A better understanding and appreciation of the human aspects of this disease is essential in devising any programme for its control, the lack of which has been the major cause of our failure. While a special leprosy programme has some advantages it has several disadvantages, such as too large an area of coverage per worker, the attachment of stigma to him with resultant lowered acceptability by the people and inability to get motivated doctors to provide leadership A vertical programme also suffers from all the other disadvantages of a government service such as lack of supervision and accountability, repeated transfers which prevent build up of rapport with patients and the community, and lack of administrative and technical support. Though few in-depth evaluations of such services are available it is generally accepted that except in a few states the performance is poor, especially when compared with the voluntary agencies. A considerable percentage of the cases are not detected and the regularity of treatment is generally less than $50 \%$ as judged by the WHO criteria.

Recently attempts have been made at integrating the leprosy service with the other health programmes at the paramedical level in the hope that this will eliminate the stigma attached to the workers, reduce the area of coverage and help establish greater rapport with the people. Unfortunately, such integration has been firmly resisted on the basis that there is a danger of losing whatever has been gained over the years.

It should be realized that many of these problems afflict the whole health delivery system of which leprosy is only a small segment. A recent joint report of the Indian Council of Social Science Research and Indian Council of Medical Research has highlighted these problems and has recommended an integrated 'bottom up' rather than a 'top down' approach which should be firmly based within the local community which should assume responsibility for its own health and for which it should be assigned both administrative and financial powers. Wherever possible the staff should be recruited from the local community and answerable to them, and the pernicious system of transfers be eliminated. Only thus can there be peoples' involvement in their own problems and ensured rapport and accountability in the persons who are employed to help them.

The report further analyses the actual problems of health and its care on the basis of the experience of several microstudies. It states that about $90 \%$ of all health care including its most important components, whether preventive, promotive or even curative is of a relatively simple nature requiring a low level 
of technical knowhow, but close cultural affinity with the people with whom it should be in close proximity. Hence it can be best carried out by the people themselves with some training and support. If any outside agency like the government tries to undertake or appropriate these tasks there results not only an increase in cost but also a failure to deliver the goods. Worse still, it generates a feeling of dependency among the community, with resultant loss of interest and absence of participation in activities for the improvement of their own health and welfare.

Leprosy fits this proposed model admirably like most other communicable diseases such as gastroenteritis, tuberculosis and malaria. In an experimental field project covering a rural population of 30,000 in north Alibag Taluka popularly known as the Mandwa project, we have trained local women as parttime health workers - one for each village of approximately 1,000 population. They are taught to undertake all forms of health care practices with special emphasis on the problems of women and children. They have also been taught the basic signs and symptoms of leprosy, namely, anaesthetic patches, thickening of the skin and ear lobules, loss of eyebrows, and palpation of the ulnar and greater auricular nerves; as also of other diseases like malaria and tuberculosis.

Prior to the commencement of the project the full-time 2-year trained government leprosy technicians working for over 10 years in the area had detected 63 cases of leprosy in this population. In a period of 3 years from 1977 to 1979, 90 other cases have been detected by this system, most of them (59) by our village workers and confirmed by the supervisory staff. It is interesting to note that most of these were early cases including those of the lepromatous variety, prior to the development of major deformities. Much more important, the regularity of dapsone treatment, as measured by the WHO criteria has increased from less than 50 to more than $90 \%$. Since the workers are local women dealing with all types of health problems and visit each house in the village at least once a month (and the at-risk cases more frequently) there arise no problems of regularity, accessibility, rapport or communication. The women mix freely with the patients and invite them to their homes thus eliminating fear and stigma in the minds not only of the patients but also of the community. It is not surprising that such constant contact ensures early detection and regularity of treatment. The stigma of leprosy does not get attached to such a local worker who looks after all health activities of the village and her word often carries more weight within her community than that of an outsider.

While a detailed study of the project is in the process of being undertaken there is ample evidence to demonstrate the higher effective nature of such an approach to leprosy, at what turns out to be a much reduced cost.

This approach has proved equally effective for other diseases such as tuberculosis, malaria, and gastroenteritis and the immunization rate has increased from 15 to over $70 \%$. 
Unfortunately, the Government Community Health Worker Scheme based on such a model has failed to achieve similar results. This is because the concept of educating the community to look after its own health problems and providing only supportive service has not been acceptable either to the medical profession or paramedical workers. They see these community health workers as a threat to their practice and also as a means of ensuring accountability. The community is hardly aware of the true nature of this scheme and are not involved in the programme. Under these circumstances such a promising avenue for health care can hardly be expected to thrive. The potential, nevertheless, exists as revealed by our studies and other similar ones, and provides us with one of the most potent weapons in our armamentarium for the control of this disease at little, if any, increase in cost. 